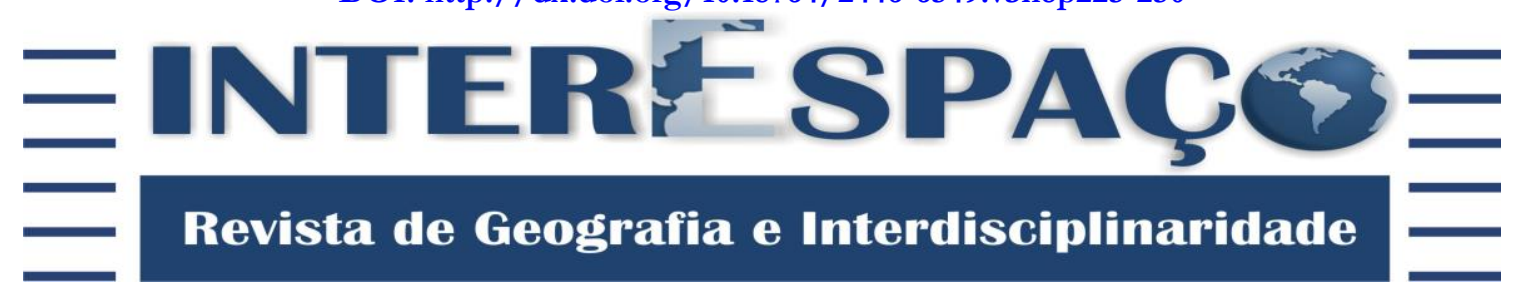

\title{
CONFLITOS E INTERESSES NO PROCESSO DE “CONSTRUÇÃO” DA RESEX MAPUÁ, MARAJÓ, PARÁ
}

\author{
CONFLICTS AND INTERESTS IN THE "CONSTRUCTION" PROCESS OF \\ ER MAPUA, MARAJÓ, PARÁ
}

\section{CONFLICTO E INTERESES EN EL PROCESO DE "CONSTRUCCIÓN" LA RESEX MAPUA, MARAJÓ, PARÁ}

\begin{abstract}
Vanessa Silva Amaral
Mestre em Planejamento do Desenvolvimento pelo Programa de Pós-graduação em Desenvolvimento Sustentável do Trópico Úmido (PPGDSU) do Núcleo de Altos Estudos Amazônicos (NAEA) da Universidade Federal do Pará - UFPA. vs.amaral@yahoo.com
\end{abstract}

\section{Jondison Cardoso Rodrigues}

Doutorando em Desenvolvimento Socioambiental pelo Programa de Pós-graduação em Desenvolvimento Sustentável do Trópico Úmido (PPGDSU) do Núcleo de Altos Estudos Amazônicos (NAEA) da Universidade Federal do Pará - UFPA. jondisoncardosorodrigues@gmail.com

Recebido para avaliação em 25/02/2017; Aceito para publicação em 23/04/2017.

\section{RESUMO}

A Amazônia é a região do Brasil que mais possui Unidades de Conservação (UC), particularmente Reservas Extrativistas (RESEX). Uma delas é a RESEX Mapuá, no Marajó (estado do Pará). Assim, o objetivo do artigo é descrever e analisar os conflitos e os interesses no processo de "construção"/criação da RESEX, em 2005. Para tal "estudo", foram realizadas: 1) pesquisas de campo (2015 e 2016); 2) relatos orais dos moradores locais, comunidades Bom Jesus, Nossa Senhora das Graças (Vila Amélia) e Lago do Socó; 3) Entrevista com membros do Sindicato dos Trabalhadores e Trabalhadoras Rurais de Breves (STTR/Breves); 4) entrevista semiestruturada com líderes comunitários (agentes da Associação de Moradores de Mapuá - AMOREMA); 5) entrevista com analista do ICMBIO (Instituto Chico Mendes de Conservação da Biodiversidade), gestor local da RESEX; 6) decreto de 20 de maio de 2005, que cria a RESEX. Para essa discussão, utilizou-se o estudo de caso associado com a teoria de campo de Pierre Bourdieu.

Palavras-chave: RESEX Mapuá; Amazônia; Política Ambiental.

\section{ABSTRACT}

Amazon Region is the Brazilian region with the most Conservation Units (CU), particularly Extractive Reserves (ER). ER Mapuá, in Marajó, is one of them. So the purpose of this article is describe and analyze the conflicts and interests in the process of "building"/creation of ER Mapuá in 2005. For this "search" were performed: 1) field surveys (2015 and 2016); 2) oral reports from the local inhabitants, communities Bom Jesus, Nossa Senhora das Graças (Vila Amélia) and Lago do Socó; 3) interviews with members of the Sindicato dos Trabalhadores e Trabalhadoras Rurais de Breves (STTR/Breves); 4) Semi-structured interview with community leaders (agents of the Associação de Moradores de Mapuá - AMOREMA); 5) Interview with an analyst from ICMBIO (Instituto Chico Mendes de Conservação da Biodiversidade), local RESEX manager; 6) decree of 
May 20, 2005 creating the RESEX. For this discussion we used the case study associated with Bourdieu's field theory.

Keywords: ER Mapuá; Amazon; Environmental Politics.

\section{RESUMEN}

La Amazonía es una región de Brasil que tiene más Unidades de Conservación (UC), en particular las reservas extractivas (RESEX). Uno de ellos es RESEX Mapua en Marajó (Estado de Pará). Así, el objetivo del artículo es describir y analizar los conflictos e intereses en el proceso de "construcción"/ creación de RESEX en 2005. Para este "estudio" se llevaron a cabo: 1) estudios de campo (en 2015 y 2016); 2) cuentas orales de los residentes locales, las comunidades Bom Jesus, Nossa Senhora das Graças (Vila Amélia) y el Lago Soco; 3) Entrevista con los miembros de la Unión de Trabajadores del Campo de Breves (STTR/Breve); 4) Entrevista semiestructurada con líderes de la comunidad (agentes Associação de Moradores de Mapuá - AMOREMA); 5) Entrevista con ICMBIO (Instituto Chico Mendes de Conservação da Biodiversidade), gerente RESEX local; 6) El decreto de 20 de mayo de 2005, por la RESEX. Para esta discusión se utilizó el estudio de caso asociado con la teoría de campo de Bourdieu.

Palabras clave: ER Mapuá; Amazonas; Política Ambiental.

\section{INTRODUÇÃO}

A “evolução" da política ambiental, principalmente para proteção de áreas de grande sociobiodiversidade (Unidades de Conservação), é caracterizada por um histórico, ao longo do século XX, de interesses conflitantes, imersos em contextos sociais e políticos (DRUMMOND; FRANCO, 2009; DRUMMOND; FRANCO; NINIS, 2009; FEARNSIDE, 2003; 2013; 2016) ${ }^{1}$. Tal "histórico" (político) tem influenciado os rumos das políticas ambientais pelo mundo, no Brasil e, mais especificamente, na Amazônia (CAVALCANTI, 2002; AMARAL, 2016).

A evolução da política ambiental brasileira pode ser analisada a partir da década de 1930, quando tiveram início ações de regulamentação da apropriação dos recursos naturais necessários ao processo de industrialização (PECCATIELLO, 2011, p. 72). A [...] Criação de áreas protegidas no Brasil, já que, desde a instituição da República, em 1889, esta questão vinha sendo tratada com imobilismo quase total [...]. Destacam-se a criação de dispositivos legais Código das Águas (1934), Código de Mineração (1934), Código Florestal (1934), Código de Pesca (1938) e Estatuto da Terra (1964); de agências setoriais ao longo da década de 1960 - Ministério das Minas e Energia, Departamento Nacional de Águas e Energia Elétrica, Instituto Brasileiro de Desenvolvimento Florestal (IBDF), Superintendência de Desenvolvimento da Pesca (SUDEPE) e Instituto Nacional de Colonização e Reforma Agrária (INCRA); e a criação e delimitação de zonas naturais protegidas - Parque Nacional do Itatiaia (1937),

\footnotetext{
${ }^{1}$ Segundo Fearnside (2013, p. 9): "O contexto das políticas ambientais brasileiras mudou de várias maneiras ao longo das últimas duas décadas, com alguns aspectos positivos para o meio ambiente e outros não. Mudanças positivas incluem a criação de um Ministério do Meio Ambiente e de um sistema de licenciamento ambiental, o aumento da organização da sociedade civil, a criação de reservas e demarcação de áreas indígena e o advento das convenções internacionais sobre o clima e a biodiversidade. No entanto, os projetos de desenvolvimento na Amazônia brasileira têm contornado as restrições ambientais de várias maneiras, e as modificações do passado e do presente no sistema estão enfraquecendo a proteção ambiental".
} 
Parque Nacional do Iguaçu (1939), Parque Nacional da Serra dos Órgãos (1939), Floresta Nacional de Araripe Apodi (1946), Parque Nacional do Araguaia (1959), Parque Nacional das Emas (1961), Parque Nacional das Sete Quedas (1961) (PECCATIELLO, 2011, p. 74).

A “evolução" da política ambiental brasileira, pontuada por Peccatiello, assinala que a criação de instrumentos e a prática de delimitação de territórios para conservação da biodiversidade foi disseminada, no Brasil, no artigo $9^{\circ}$ do Código Florestal e na Constituição Federal de 1934, com forte influência da criação de unidades de conservação nos Estados Unidos (DRUMMOND; FRANCO; NINIS, 2009). Entretanto, nos termos de Silva (2007), Dumith (2013) e Costa e Murata (2015), a consolidação de uma legislação única que englobasse os principais aspectos de criação, implementação, manutenção, regulação do acesso, uso e manejo de recursos naturais e fiscalização em prol de um uso e desenvolvimento sustentável do ambiente (protegido por Lei) só viria a ocorrer no ano 2000, com a Lei 9.985/2000, que instituiu o Sistema Nacional de Unidades de Conservação da Natureza (SNUC).

Tanto a criação desse dispositivo regulatório quanto a criação do SNUC podem ser consideradas estratégias institucionalizadas de proteção sistêmica da natureza (AMARAL, 2016), como pano de fundo, segundo Paulino e Cunha (2014) e Dumith (2013):

\footnotetext{
Argumentamos que o processo de criação de UCs pode ser lido como parte dos esforços de modernização de determinados espaços pela via institucional processo de criação de UCs pode ser lido como parte dos esforços de modernização de determinados espaços pela via institucional. Isto é, a operação do Estado e de outros atores no sentido de promover uma atualização das relações sociais através da constituição de novos arranjos institucionais, que levam a uma racionalização crescente dos modos de vida nestes espaços, ocupados por setores da sociedade [...] (PAULINO; CUNHA, 2014, p. 30).

As UC, como um todo, vêm sendo concebidas como "inovações institucionais" para a gestão socioambiental, orientadas para atender, pelo menos, duas grandes metas de conservação, que muitas vezes se contradizem ou entram em conflito entre si: a criação de UC de Proteção Integral para garantir a preservação e manutenção das funções ecológicas de fragmentos ecossistêmicos considerados prioritários; e o estabelecimento de UC de Uso Sustentável orientadas para a proteção e conservação dos modos de vida das populações tradicionais (DUMITH, 2013, p. 7).
}

As RESEX surgem com a finalidade de gerar desenvolvimento social e proteção ao meio ambiente, objetivando também a inclusão social e econômica das populações que vivem dentro ou no entorno dessas áreas (COSTA, MURATA, 2015; SILVA; SIMONIAN, 2015). Para Silva (2007, p. 295-296), “as RESEX foram efetivamente a primeira grande síntese amazônica moderna não-indígena de um novo modelo de desenvolvimento humano local, associada ao ideário de preservação dos ecossistemas naturais com base em áreas protegidas". 
Apesar da estruturação jurídico-legal (a criação de UC) e a contenção ao desflorestamento (MARQUES; SCHNEIDER; PERES, 2016), as RESEXs também contribuíram para o surgimento e a intensificação de conflitos sociais, econômicos, culturais, étnicos (SILVA, 2007; SILVA, 2015; SILVA; SIMONIAN, 2015).

Segundo Costa e Murata (2015, p. 96):

[...] muitos dos conflitos socioambientais envolvendo grupos sociais e UC ocorrem devido à implantação de unidades de Proteção Integral, de caráter restrito à ocupação e uso humano. Essas populações são então realocadas ou indenizadas e precisam restringir seu uso e acesso a alguns recursos naturais. Sendo essas atividades praticadas consuetudinariamente e, sendo essas populações detentoras dos direitos da propriedade, cria-se um conflito e um debate entre essas duas vertentes.

Muito dos conflitos "vieram"/emergiram a partir: i) da criação das RESEX; ii) da intervenção mais macro e intersetorial das políticas públicas para UC (assistencialistas e paliativa); iii) precária situação das áreas: educacionais, de moradia e de saneamento básico, problemas de saúde, assistência técnica para gestão da produção agrícola sustentável/sustentada e regularização fundiária (SILVA, 2007; COSTA, 2014).

Dois outros conflitos, muito comuns, segundo Amaral (2016), resultam: (1) da conduta de diálogo, baseada no estatuto, de técnicos/especialistas (messiânicos), consultores e experts responsáveis por povos ou populações locais que são incapazes de se autogerir² ; (2) dos equívocos e contradições dos conselhos deliberativos (SILVA et al., 2013).

Considerando essa discussão, o objetivo deste artigo é descrever e analisar os conflitos e os interesses no processo de "construção"/ criação da RESEX Mapuá, em 2005. A relevância desse estudo justificava-se pela necessidade de mostrar como se dá o processo de construção de uma RESEX, quais os interesses que estão em jogo, as disputas, os conflitos e os impactos.

\section{METODOLOGIA}

\section{Área de estudo}

\footnotetext{
${ }^{2}$ Há um vício dos técnicos dos órgãos públicos, de classificar ou ordenar hierarquicamente indivíduos ou grupos considerados minoritários, baseado, sobretudo, na fórmula básica: distinção, pequenez, homogeneidade e autossuficiência (SILVA, 2015).
} 
| Conflitos e interesses no processo de “construção” da RESEX Mapuá, Marajó, Pará|

| Vanessa Silva Amaral | Jondison Cardoso Rodrigues |

A Amazônia é composta por uma imensa diversidade sociocultural, de biodiversidade e de desigualdade social ${ }^{3}$ (AMARAL, 2016; COSTA, 2016), como também pelo mosaico de UC. A Amazônia possui 127 UC, dos quais 45 RESEX. Abaixo, pode-se visualizar arquipélago do Marajó, no estado do Pará (são quatro RESEX, Figura 1):

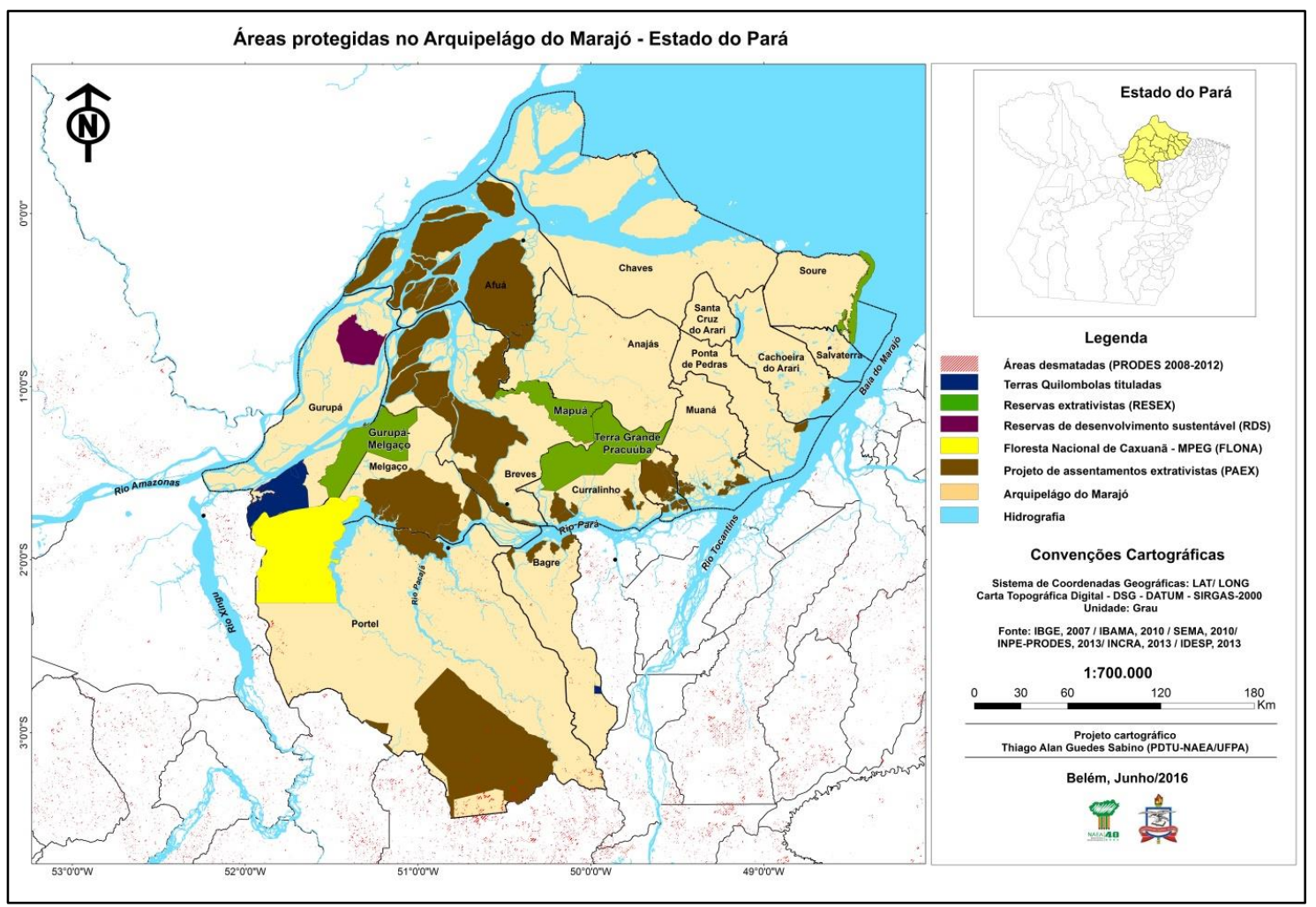

Figura 1 - Mapa das áreas protegidas no arquipélago do Marajó, Pará.

A RESEX Mapuá é caracterizada por uma teia de rios, igarapés, furos e lagos. Sendo os principais rios: Mapuá, Aramã, Lago do Jacaré; cujas comunidades locais fazem uso de óleos, sementes e látex, extraídos das espécies Seringueira (Hevea brasiliensis), Açaí (Euterpe oleracea), Andiroba (Carapa guianensis), Virola (Virola surinamensis Warb). A agricultura é praticada em alternância com o extrativismo do Açaí. As principais culturas produzidas

\footnotetext{
3 "Referente à linha de pobreza, o percentual de pobres (incluindo os extremamente pobres) na região chegou ao patamar de 57\% do total da população, ou seja, são mais de 277 mil habitantes vivendo com menos do necessário para atender as necessidades básicas de um ser humano, sendo a maior Taxa de Pobreza do Estado do Pará. No entanto, comparando a Taxa de Pobreza no Marajó em 2000 e 2010, observa-se uma redução de $10,10 \%$, contudo, em números absolutos a quantidade de pessoas pobres na região aumentou em 22.307, ou seja, enquanto a população aumentou $27,97 \%$ o número de pobres aumentou 8,73\% no período" (COSTA, 2016, p. 57). A definição de linha de pobreza usada [...] refere-se a "todas as pessoas que vivem em domicílios cuja renda domiciliar per capita é inferior a $1 \frac{2}{2}$ salário mínimo” [...]. Este recorte é baseado no conceito de pobreza absoluta, na qual é fixado um nível mínimo ou suficiente para atender as necessidades básicas de uma população. Deste modo, todos que apresentam padrões abaixo, encontram-se na situação de pobreza (FAPEPA, 2015s, não paginado). "Quatorze dos dezesseis municípios possuem mais de 50\% do total de habitantes vivendo nessa condição, e somente Soure e Salvaterra possuem menos, mesmo assim, o número de pobres passa de 1/3 do total da população. Em números absolutos Breves, Portel e Anajás, nessa ordem, possuem o maior número de pobres".
} 
são mandioca, milho, batata doce e cana-de-açúcar. A produção de farinha também se destaca entre as atividades desenvolvidas peles famílias (LOURENÇO, 2016).

A reserva é ocupa por 2.877 pessoas, as quais residem em 16 comunidades e sobrevivem da agricultura e do extrativismo. Os municípios de Anajás, São Sebastião da Boa Vista e Curralinho fazem limite na dimensão leste do município de Breves (AMARAL; FREITAS, 2016); têm seu limite ao sul e ao oeste pelo próprio Rio Mapuá (LOURENÇO, 2016).

Segundo Lourenço (2016), a formação socioeconômica da RESEX Mapuá se deu (assim como em toda a Amazônia) por meio do uso dos rios e a ocupação das suas margens. De acordo com Pinto (2008), as margens do Rio Mapuá foram inicialmente ocupadas pelos Índios Mapuás, que teriam migrado da região do estado do Amapá (PINTO, 2008).

Segundo Cornetta (2016):

\begin{abstract}
As terras que hoje formam a unidade de onze comunidades às margens do Mapuá, incluindo a comunidade Bom Jesus (onde encontramos os interlocutores dessa pesquisa), pertencem historicamente a inúmeras famílias que se estabeleceram na região, cuja ancestralidade milenar, provavelmente, de um lado, dos Nheengaíba e, uma ancestralidade mais recente, porém secular, de cearenses que migraram para região para trabalhar nas colocações de borracha no fim do século XIX, início do XX (CORNETA, 2016, p. 94)

O modo de vida dos moradores do rio Mapuá estão marcadas por suas práticas habituais com um profundo enraizamento com a várzea e os corpos d'água, valorizado pelos saberes ancestrais e pelos laços de parentesco e vizinhança, característicos da vida camponesa (CORNETA, 2016, p. 95).
\end{abstract}

Ainda com relação a isso, Pinto (2008) acrescenta que: “[...] a área que compreende a RESEX Mapuá também recebeu ocupação europeia no início do século XX. Ocupação esta que foi atraída pelo extrativismo vegetal da seringueira (Hevea brasiliensis), para a extração do látex para a produção da borracha” (PINTO, 2008, p. 93).

\title{
ABORDAGEM TEÓRICO-ANALÍTICA, FONTES E TÉCNICAS DE COLETA: construção do objeto de estudo
}

A construção do objeto científico é forjada de um processo interativo, entre teoria, empiria e síntese analítico-crítica (BACHELARD, 1996). Esse processo interativo é ainda mais pertinente, pois, segundo Castro (2008; 2010), a realidade social Amazônica não é somente múltipla e complexa, em seus aspectos sociobioculturais, mas é também "formada" (estruturada) de práticas sociais, lógicas, de racionalidades diferentes e conflitantes, devido à participação e interesses de diversos agentes. Assim, a abordagem 
(qualitativa) teórico-analítica guia é teoria de campo de Pierre Bourdieu. Essa teoria concebe que

O social é constituído por campos, microcosmos ou espaços de relações objetivas, que possuem uma lógica própria, não reproduzida e irredutível à lógica que rege outros campos. O campo é tanto um "campo de forças", uma estrutura que constrange os agentes nele envolvidos, quanto um "campo de lutas", em que os agentes atuam conforme suas posições relativas no campo de forças, conservando ou transformando a sua estrutura (BOURDIEU, 1996, p. $50)$.

A escolha dessa teoria deve-se ao fato não somente de possibilitar a apreensão e análise da totalidade (AMARAL, 2016), mas porque

Tomando como ponto de partida a assertiva segundo a qual o mundo humano é simbolicamente construído, entendemos que (ao contrário dos que defendem posições quanto a formulações consensuais e (ou) quanto à "universalidade" de valores e interesses no trato das questões ambientais) existem concepções múltiplas de natureza e (ou) meio ambiente - categoriais sociais constituídas pela sociedade e relativas ao homem (VIÉGAS, 2009, p. 146).

As concepções múltiplas de natureza ou meio ambiente, pontuadas por Viégas, assinalam que as visões dos "atores sociais" são diferentes entre si, pois são dispostas de habitus $^{4}$, no qual o mundo é simbolicamente construído e conservado (BOURDIEU, 1994). “Isso significa que dentro desse campo ${ }^{5}$ que pode dizer de o 'Campo da UC', os conflitos estarão imersos tanto por disputas territoriais quanto político-institucionais-jurídicas entre o Estado e os atores sociais" (AMARAL, 2016, p. 107).

Outro motivo da "escolha" dessa abordagem teórico-analítica guia, deve-se ao fato de que, metodologicamente, este tipo de pesquisa possibilita generalizar para outras instâncias, a partir da noção de Campo, sendo assim facilmente coassociado ao estudo de caso. Cabe destacar que o estudo de caso, conforme Yin (2005),

Como estratégia de pesquisa, utiliza-se o estudo de caso em muitas situações, para contribuir com o conhecimento que temos dos fenômenos individuais, organizacionais, sociais, políticos e de grupo, além de outros fenômenos relacionados. [...] Em todas essas situações, a clara necessidade pelos estudos de

\footnotetext{
${ }^{4}$ Esse grupo mobilizado (Campo), para Bourdieu (2001), seria um sistema autônomo, composto de um espaço plural de agentes, no entanto, com acepções linguísticas específicas e mecanismos genéricos (regras). Um espaço social de disputas para a aceitação ou a eliminação de conflitos ou um espaço de luta por classificações entre os diferentes produtores, que podem determinar a aparição de produtos sociais relativamente independentes de suas condicionantes sociais de produção, cuja (re)produção perfaz-se como verdades cristalizadas (BOURDIEU, 1994, 2002a).

${ }^{5}$ Habitus é um sistema de (de disposições adquiridas) esquemas de percepção, apreciação e ação fundados no mapeamento, reconhecimento e incorporação de estímulos condicionais e convencionais que tendem reproduzir a lógica objetiva dos condicionamentos, reproduzindo relações sociais objetivas (BOURDIEU, 2002b), formando esquemas classificatórios, princípios de classificação, princípios de visão (BOURDIEU, 1994).
} 
caso surge do desejo de se compreender fenômenos sociais complexos. Em resumo, o estudo de caso permite uma investigação para se preservar as características holísticas e significativas dos acontecimentos da vida real [...] (YIN, 2005, p. 20).

Em síntese, o uso do estudo de caso (RESEX Mapuá), juntamente com a teoria de campo, conseguem apreender um fenômeno social de forma mais complexa, já que possibilitam visualizar, com maior destreza, o jogo que está sendo jogado (e os interesses); um jogo de disputas no qual os atores sociais procuram ter certo reconhecimento no campo em que atuam (AMARAL, 2016). Sendo assim, trata-se de um dispositivo teóricometodológico para identificar e analisar os tipos de regras, os jogos e os conflitos sociais, como também determinados jogos de interesses e seus respectivos impactos.

Segundo Yin, para desenvolver um estudo de caso de alta qualidade é fundamental se ter pelo menos seis fontes de evidências, que, no caso da pesquisa (sintetizada nesse artigo) foram: 1) pesquisas de campo (em 2015 e 2016 ${ }^{6}$; 2) relatos orais dos moradores locais, comunidades Bom Jesus, Nossa Senhora das Graças (Vila Amélia) e Lago do Socó; 3) entrevista com membros do Sindicato dos Trabalhadores e Trabalhadoras Rurais de Breves (STTR/Breves); 4) entrevista semiestruturada com líderes comunitários (agentes da Associação de Moradores de Mapuá - AMOREMA); 5) entrevista com analista do ICMBIO (Instituto Chico Mendes de Conservação da Biodiversidade), gestor local da RESEX; 6) o Decreto de 20 de maio de 2005, que cria a RESEX.

\section{RESERVAS EXTRATIVISTAS: uma construção lenta e insustentável}

O Brasil possui 326 Unidades de Conservação (UC) federais geridas pelo Instituto Chico Mendes de Conservação da Biodiversidade (ICMBIO), espalhadas em todos os biomas brasileiros - Amazônia, Caatinga, Cerrado, Mata Atlântica, Pampa, Pantanal e Marinho - cuja área total (em hectares) das UC são de 1.203.940.363,087. Segundo o ICMBIO, dessas 326 UC, 137 são UC de Proteção Integral e 189 são UC de Uso Sustentável (ICMBIO, 2017a).

A Amazônia é a região do Brasil que mais possui UC, particularmente RESEX. Segundo ICMBIO (2017a), são 127 UC na Amazônia; dessas, 45 são RESEX. Cinco no

\footnotetext{
${ }^{6}$ As pesquisas de campo, em 2015, foram realizadas nos seguintes períodos: 17 a 20 de junho; 23 a 31 de julho; 12 a 18 de agosto; e, outubro e novembro, de 27 a 07. Já a pesquisa de campo ocorreu em 2016, de 12 a 19 de janeiro.

${ }^{7}$ Em termos percentuais, os biomas representam a seguinte distribuição: Amazônia (15,2\%), Caatinga (3,9\%), Cerrado (3,2\%), Marinho costeiro (0,2\%), Mata Atlântica (3,8\%), Pampa (2,1\%) e Pantanal (1,0\%) (ICMBIO, 2017a).
} 
estado do Acre, 1 no Amapá, 23 no Pará, 10 no Amazonas, 4 em Rondônia e 1 no Tocantins. Note-se que nesse bioma, Roraima é o estado onde não se instituiu nenhuma UC (ICMBIO, 2017b).

Para além da configuração já posta de UC e do debate (e disputas) de preservação e conservação (BEZERRA; LIMA, 2015), é preciso mostrar uma espécie de "itinerário tortuoso" de construção de UC na Amazônia, principalmente de RESEX.

A construção de UC na Amazônia é marcada não pela forest of disputes (IORIS, 2005) da população tradicional, mas, sobretudo, pela luta pela terra e pelo acesso e gestão de recursos naturais (ALLEGRETTI, 1992). Esta última, baseada numa proposta de estatuto territorial resultante do processo de "lutas e experiências acumuladas que tornaram possível idealizar esse espaço" (ALLEGRET'TI, 2002; SANTOS, 2015).

Essa construção lenta, com lutas, é pontuada do seguinte modo por Allegretti (1992; 2008), acerca das políticas implantadas na Amazônia:

\begin{abstract}
As políticas implantadas na Amazônia, nas últimas décadas, resultaram da busca de soluções para problemas externos à região. No caso dos projetos de colonização, a Amazônia foi vista como espaço vazio e como forma de evitar a realização de uma reforma agrária no Centro-Sul. No caso dos projetos agropecuários e minerais, a Amazônia passou a ser entendida como fronteira de recursos para setores econômicos estabelecidos fora da região. As atividades implantadas nesse período desagregaram o ambiente e não aumentaram a renda regional. Uma política de uso dos recursos naturais renováveis para a Região Amazônica deve ter essa perspectiva invertida e ser concebida em consonância com as prioridades regionais. Devem ser adotadas medidas estruturais como o zoneamento ecológico-econômico e políticas setoriais, econômicas e sociais que permitam uma reconciliação entre o uso do potencial de recursos existentes e uma adequada distribuição de renda. Para isso, ao lado da restrição ao uso, através da criação de unidades de conservação, é preciso encontrar formas de promover, por meio de instrumentos institucionais adequados, a utilização dos recursos existentes. [...] (ALLEGRETTI, 1992, p.146, grifo nosso).

As Reservas Extrativistas foram concebidas como territórios contínuos que não deveriam ser divididos, como ocorria com a reforma agrária convencional, de propriedade da União, para usufruto de comunidades com tradição no uso sustentável dos recursos naturais, por meio de contratos de concessão de uso, condicionados a planos de manejo dos recursos (ALEGRETTI, 2008, p. 47).
\end{abstract}

Até a criação da primeira $\operatorname{RESEX}^{8}$ na Amazônia houve um longo caminho:

\footnotetext{
8 Para Allegretti (1992, p.150), as Reservas tinham de ser criadas com os seguintes pressupostos: “As reservas extrativistas são espaços territoriais protegidos pelo Poder Público, destinados à exploração autossustentável e conservação dos recursos naturais renováveis, por populações com tradição no uso de recursos extrativos, reguladas por contrato de concessão real de uso, mediante plano de utilização aprovado pelo órgão responsável pela política ambiental do País (IBAMA)”. Hoje, segundo a Lei no_9.985, de 18 de julho de 2000, que institui o Sistema Nacional de Unidades de Conservação da Natureza, no Capítulo III, Art. 18: A Reserva Extrativista é uma área utilizada por populações extrativistas tradicionais, cuja subsistência baseia-se no extrativismo, complementarmente, na agricultura de subsistência e na criação de animais de pequeno porte, tendo como objetivos básicos proteger os meios de vida e a cultura dessas populações, assegurando o uso sustentável dos recursos naturais da unidade.
} 
| Vanessa Silva Amaral | Jondison Cardoso Rodrigues |

A proposta de criação de reservas extrativistas na Amazônia teve uma formulação inicial no âmbito do Programa Nacional de Reforma Agrária, recebendo a denominação de Projeto de Assentamento Extrativista, através da Portaria $\mathrm{n}^{\circ}$ 627, de 30 de julho de 1987, do Incra. A partir de 1989, as reservas extrativistas passaram a fazer parte do Programa Nacional de Meio Ambiente, tendo sido regulamentadas através do Decreto no 98.897 , de 30 de janeiro de 1990. As duas denominações não expressam conteúdos diferentes, mas sim responsabilidades institucionais distintas. Além disso, enquanto a primeira requer regularização fundiária prévia à criação, por ser uma unidade de reforma agrária, a segunda, por ser considerada como unidade de conservação, permite a imobilização de áreas para fins de uso sustentável e posterior regularização (ALLEGRET'TI, 1992, p. 150).

Todo esse cenário trazia consigo, inclusive, segundo discurso de Allegretti, a ideia de que com a UC haveria um espécie de restrição ao uso de recurso (no fragmento em negrito acima). Isso também gerou uma série de conflitos, com as "populações tradicionais", por meio dos empates, movimento conhecido por "empatar" a derrubada das árvores para a criação de pastos.

De acordo com o exposto por Allegretti (1992), o Projeto de Assentamento Extrativista era de 50 até 100 hectares e uma colocação de seringa ocupava, em média, 300 a 500 hectares, dependendo do número de filhos em idade de trabalhar e de estradas de seringa, além dos pequenos roçados e dos castanhais. Já é possível perceber que este novo modelo impactou diretamente no modo de vida tradicional das populações. Nesse sentido, ocorreram novos debates para discutir políticas públicas para essas áreas (CUNHA, 2010).

Santos e Marin (2016, p. 272) fazem uma crítica densa sobre a construção das UC:

Incorporamos ainda a esse debate uma crítica à criação das Unidades de Conservação (UCs) no Brasil, que são entendidas dentro da política ambiental do governo brasileiro como estratégia para a conservação da natureza. $\mathrm{Na}$ década de 1960, algumas UCS foram implementadas pelo governo militar de maneira arbitrária e autoritária baseada na negligência histórica das comunidades que ocupavam essas áreas, fundamentando-se ainda na visão de conservação da vida selvagem e da concepção naturalista de áreas protegidas enquanto "ilhas de biodiversidade" ameaçadas pelo avanço civilizatório urbano-industrial [...]. Ademais, mesmo com a criação das UCs de uso sustentável como a Reserva Extrativista (Resex) e a Reserva de Desenvolvimento Sustentável (RDS), estas não foram suficientes para cessar conflitos socioambientais envolvendo comunidades tradicionais. Ou seja, tem ocorrido o aumento da marginalização dessas populações que inúmeras vezes aparecem como "ilegais" frente as autoridades ambientais que tratam como ato criminoso tais relações tradicionais.

Ainda com relação ao pontuado por Santos e Marin, Freitas, Florentino e Souza $(2015)^{9}$ relatam muitos problemas nas RESEX:

Com base no depoimento dos entrevistados, nota-se que os moradores estão muito insatisfeitos com a forma que vem sendo tratados pelos gestores, a

\footnotetext{
9 Objetivo do artigo dos autores foi avaliar os resultados das intervenções públicas no período de duas décadas na Reserva Extrativista do Alto Juruá - REAJ (AC), considerando o modelo de gerenciamento implementado pelo Estado nas UC da Amazônia Brasileira.
} 
exemplo da falta de compromisso, ausências de visitas periódicas, programas e projetos que os diferencie de animal irracional selvagem e/ou domesticado que vive com muita dificuldade em espaço limitado à sobrevivência. Estamos falando de atores humanos que pensam e sentem das mais distintas necessidades tanto quanto aqueles que trabalham em escritórios luxuosos despachando decisões arbitrárias sem ao menos consultar e conhecer a verdadeira realidade dos povos tradicionais que residem em meio às florestas tropicais, a mercê da fome, frio, doenças e animais selvagens.

As políticas de comando e controle da forma como vem sendo aplicadas implicam na mudança de atitude de cada indivíduo da REAJ, fazendo com que os moradores passem a pensar como fazendeiros e não mais como seringueiros que apostaram imensuravelmente conquistar o sonho da proteção e apoio do Estado.

O estágio que se encontram as unidades de conservação de uso sustentável (Reservas Extrativistas) pode ser denominado de UCs que promovem pobreza e estimula agressão a natureza. É importante salientar que teoricamente o estatuto e as leis asseguram lindas maquetes dos moradores vivendo em nível elevado de qualidade de vida e plena harmonia com os recursos ambientais, porém, com base nas constatações em campo fomos levados a acreditar que este estudo debateu Reservas Extrativistas de uso (in) sustentável (FREITAS; FLORENTINO; SOUZA, 2015, p. 18).

Santos Junior (2006) argumenta, no seu estudo sobre a RESEX de Soure, que a criação dela não alterou de forma significativa a vida da população local no que diz respeito ao quesito socioeconômico. Esta UC possuiria problemas graves como a falta de abastecimento de água potável. Ainda em relação à referida RESEX, Cardoso (2015) afirma que a maior dificuldade da população local, que se utiliza da pesca para subsistência, é a política de desenvolvimento para a região que não apresenta uma visão endógena e isso influencia, de forma negativa, diretamente na vida da população local.

Essa "sustentabilidade" pautou-se, sobretudo, porque, conforme Cardoso (2015), o modelo de desenvolvimento foi norteado apenas na preocupação conservacionista vinculada à problemática ambiental universal e não nas especificidades do povo amazônico. Marin (2015) afirma que as UC são criadas no Marajó com o objetivo de preservação da floresta e contenção do desmatamento e devastação, todavia não têm contribuído eficientemente com a melhoria da vida dos povos e comunidades tradicionais.

Segundo Cardoso (2015, p. 131), é certo que a criação das RESEX foi uma "[...] conquista política dos seringueiros como instrumento para conservar os recursos, garantir suas formas de existência e de organização política", porém, o que se vê, na prática, nas UC, são os mesmos problemas existentes antes da institucionalização.

\section{RESEX MAPUÁ: interesses e conflitos}

A RESEX Mapuá foi à segunda RESEX criada no arquipélago do Marajó. A primeira RESEX é a Reserva Extrativista Marinha de Soure (27.463 ha/Município de 
Soure). Depois da RESEX Mapuá, ainda foram criadas: Reserva Extrativista GurupáMelgaço (145.297 ha/Municípios de Gurupá e Melgaço), em 2006; Reserva Extrativista Terra Grande Pracuúba (184.917 ha/Municípios de Curralinho e São Sebastião da Boa Vista), em 2006. Todas elas criadas, segundo Amaral (2016), com sérios problemas, dentre os principais, a falta de autonomia e conflitos entre gestores e a população local.

A criação da RESEX Mapuá foi para além da visão romântica (isto é, sem conflitos), com "etapas burocráticas": i) audiências e consultas públicas com as partes interessadas, para assegurar os direitos e regras de uso; ii) definição de critérios para a gestão compartilhada entre as instituições públicas e as associações de moradores locais, representadas por sindicatos ou outras Organizações Não-Governamentais (ALVES; SILVA; CASTRO, 2014).

\title{
A CONSTRUÇÃO CONFLITUOSA ${ }^{10}$ NA RESEX MAPUÁ
}

\author{
Segundo Cornetta (2016, p. 100):
}

Em fins do século XIX, duas famílias atraídas pelas possibilidades econômicas da borracha, fixaram residência nas terras cortadas pelo rio Mapuá e passaram a disputar o controle daquelas várzeas. De um lado, na margem esquerda, Constantino Martins Félix, imigrante português, do outro, Antônio Joaquim Nascimento, migrante de origem cearense, foram pioneiros na exploração da borracha com base no aviamento naqueles lados do Marajó. [..] No final dos anos 1960, já com a "propriedade" nas mãos daquela família, a economia da borracha é substituída pela extração da madeira. Com a vasta cobertura vegetal da região do Marajó, particularmente na região dos Furos de Breves, o comércio de madeira cresce exponencialmente com as exportações de espécies abundantes como virola, andiroba, maçaranduba, cupiuba, entre outras de menor expressão comercial. Essa riqueza vegetal converteu-se na principal atividade econômica do município, direcionada tanto para o mercado doméstico local e nacional, atingindo, inclusive, escalas de exportação significativas.

Ainda segundo Cornetta (2016, p. 100-1):

Na virada da década de 1970 para 1980, multinacionais madeireiras passaram a
atuar no município. Destacam-se, tanto em Breves, como nos municípios
vizinhos, as empresas Radex e Brumasa, como as principais exportadoras de
madeira beneficiada.
Pouco antes da chegada das multinacionais, no início dos anos 1970, já
despontavam algumas empresas de porte considerável, como a Superfine

10 Para Acselrad (2004), os conflitos ambientais envolvem grupos sociais que possuem diferentes visões acerca da apropriação, uso e significação do território. De acordo com Little (2001, p. 1959), "[...] podemos definir os conflitos socioambientais como disputas entre grupos sociais derivadas dos distintos tipos de relação que eles mantêm com seu meio natural". Para o referido autor, são três as tipologias dos conflitos socioambientais: conflitos que envolvem controle dos recursos naturais; os impactos advindos da ação humana e natural; e aqueles que envolvem o uso dos conhecimentos ambientais. Acselrad (2014, p.31) aduz ainda que os "[...] conflitos ambientais tendem a traduzir as tensões em torno aos padrões de apropriação do espaço associados aos modelos de desenvolvimento". 
| Vanessa Silva Amaral | Jondison Cardoso Rodrigues |

\begin{abstract}
Madeireira Ltda., com participação majoritária de capital japonês. Trata-se de um acordo estabelecido com a família Félix, em que a empresa assume o comando da área de 98 mil hectares, às margens do Mapuá, e os "patrões", os Félix, continuavam com o controle da área. No fim da década de 1970, a empresa muda de nome e passa se chamar Santana Madeireira Ltda. e começa a investir em uma fábrica de lambril no município de Santana, estado do Amapá. A relação estabelecida entre a empresa e os antigos "donos", isto é, o explorador do trabalho no interior das comunidades ribeirinhas, era de responsabilidade mútua. De um lado, enquanto a empresa garantia a compra da madeira, por outro, “o 'patrão' mantinham a relação de subordinação com os extrativistas, por meio de mecanismos de endividamento e dependência [...]" (Herrera, 2003, p. 61). Com o fechamento da om o fechamento da empresa em 1978, e sem nenhum interesse em manter o controle efetivo da área, essas terras voltam para a responsabilidade dos Félix. Com o encerramento das atividades da empresa e o decorrente abalo à economia local, os conflitos pela posse da terra tornavamse mais acirrados. Mesmo com os conflitos latentes, o controle das terras permanece com a família Félix que continua a explorar o corte de madeira, porém sem a mesma intensidade com a diminuição da madeira de lei.
\end{abstract}

Todo esse contexto, aludido por Corneta, contribuiu para que a criação da RESEX Mapuá fosse conflituosa (conflitos fundiários e uso de recursos naturais). Segundo entrevista realizada com o então líder sindical de Breves (na época que antecedeu a criação da RESEX), do Sindicato dos Trabalhadores e Trabalhadoras Rurais de Breves (STTR Breves):

\begin{abstract}
Exatamente no ano de 2000 teve um conflito agrário com a madeireira Ecomapuá ${ }^{11}$ que antes era Madeira Santana e o proprietário vendeu pro chinês chamado Lapichã aí o chinês colocou várias regras lá que impossibilitava os moradores lá da área a fazer as suas atividades que estavam acostumados a fazer. Aí gerou um conflito e a partir daí o sindicado entrou [...] tentando resolver o problema aí foi feita várias reuniões nas comunidades aí chegamos à conclusão que para resolver o problema teríamos que criar uma unidade de conservação. Aí depois a gente passou a discutir o modelo de unidade; se seria o PAEX, RDS ou se seria uma RESEX. Bom, todo mundo concordou que seria uma RESEX também porque a área lá era mais apropriada pro modelo de regularização. Então a partir daí a gente começou a trabalhar; a pegar as assinaturas. A gente pegou várias assinaturas lá e enviamos, na época era o CNPT, que era um, digamos assim, um braço do IBAMA que cuidava dessa parte de regularização fundiária dentro do IBAMA. E a gente solicitou a criação de unidade de conservação no modelo RESEX e a gente procurou também um apoio aí da prefeitura, dos órgão aí (EMATER) muitos desses órgãos aí que assinaram dizendo que eram favorável a essa criação e o CNPT mandou os técnico fazer a vistoria e achou viável a proposta. Então no dia 20 de maio de 2005 aí eu estive, fui convidado pra estar presente na assinatura do Decreto de criação da RESEX. Então foi dia 20 de maio de 2005 no Palácio do Planalto, eu estive lá, quando o presidente Lula assinou o Decreto (A. M., líder sindical de Breves, entrevista realizada em janeiro de 2016). (informação verbal).
\end{abstract}

${ }^{11}$ A ECOMAPUA CONSERVAÇÃO LTDA. é uma empresa florestal privada, criada para fornecer produtos e prestar serviços na área de reflorestamento, conservação, produção de energia renovável, óleos vegetais, biocombustíveis e carbono. A empresa foi fundada em 2000, com sede em São Paulo e escritório em Belém, estado do Pará, Brasil, e é parte integrante da holding BIO-ASSETS. A ECOMAPUA. Possui terras próprias, com cerca de 100 mil hectares, na Ilha de Marajó, estado do Pará, Amazônia, onde executa projetos de reflorestamento de espécies nativas, conservação de florestas e da biodiversidade, dando partida em um dos primeiros projetos de Redução de Emissões de Desmatamento Evitado (REDD) em área privado do Brasil. A ECOMAPUA também atua no mercado de energias renováveis, utilizando resíduos florestais, e na produção de óleos vegetais, para finalidades diversas, incluindo biocombustíveis (ECOMAPUÁ, 2016). 
De acordo com o então líder sindical e o relato de alguns moradores, esta iniciativa foi crucial para que a população se tornasse livre dos patrões (na maioria madeireiros) que comandavam os rios Mapuá e Aramã. Os referidos patrões, ainda segundo o relato do líder sindical, dominavam mais o rio Mapuá, por este concentrar maior número de trabalhadores, bem como recursos naturais (MAGALHÃES, 2014; AMARAL, 2016). Após o Decreto de 20 de maio de 2005, alguns desses patrões ainda tentaram resistir, para recuperar as terras que diziam ser deles:

Eles quiseram [resistir]. Alguns vinham pra delegacia. Teve um lá do Aramã, o cidadão dizia que era dono lá mandou chamar na delegacia seis intimados. Aí eu fui lá com eles lá. Aliás eles me ligaram e disseram que não tinham como vim. Aí eu disse: vem um só. Aí veio só o que é irmão do Galo, o Nato. E o cara lá [patrão] com advogado. Aí chegou querendo identidade do cara e mostrei o Decreto. Aí começaram a pegar os depoimentos e aí o escrivão tava pegando os depoimento e o delegado passou lá e perguntou pelos outros cinco e eu disse que não tinham ido, só tinha um. Ele ainda quis tirar barato perguntando se eu era advogado deles e eu disse que era apenas uma liderança sindical. Aí eu falei que os moradores não vinham mais por intimação por terra porque eles tem o Decreto, agora a questão não é mais com os moradores, tem que procurar o INCRA. Aí ele foi embora e depois voltou pedindo uma cópia do Decreto. Eu digo "olha, pega, mas a questão é que vocês tem que procurar o INCRA. O ribeirinho está lá não tem mais nada a ver com isso. Se vocês realmente for os proprietário o INCRA vai indenizar vocês". Mas não teve jeito pra eles porque o documento que eles tinham era só de cartório e cartório não regulariza terra. Eles não mandaram intimar mais, mas a princípio era assim; delegacia. O delegado dizia "olha, se não sair eu vou mandar prender e tal". Mas depois, como ele viu que não ia dar certo... não dava mais certo ele fazer aquela intimidação como antes, quando o ribeirinho não tinha como se defender. Antigamente eles eram intimados e tinham que vim pra cidade, mas não tinham nem recurso porque só tinham dinheiro se o patrão desse. Aí depois desistiram. [Grifo da autora] (A. M., líder sindical de Breves, entrevista realizada em janeiro de 2016). (informação verbal).

Em vista disso, na visão do líder sindical, a criação da RESEX melhorou bastante a vida dos moradores locais, pois estes não vivem mais conforme as regras ditadas pelos patrões. Ou como enfatiza o analista do ICMBIO, em entrevista, ao falar da atuação do Estado e a criação da RESEX Mapuá:

As ações do Estado são como uma necessidade emergencial de intervenção do Estado sobre uma situação de miséria absoluta em que as pessoas foram historicamente submetidas. O processo de ocupação desses territórios sempre foi extremamente coronelista, extremamente patronal. As pessoas, os nativos como se dizem, aquelas pessoas que formam as populações tradicionais sempre foram fornecedoras de mão de obra barata, matéria prima barata sem a menor possibilidade de segurança no trabalho. Então sempre praticamente se entregou [a produção]. Houve um momento histórico da RESEX Mapuá em que essa população entregava a sua produção apenas para viver no local porque as pessoas de fora; grandes comerciantes da região se intitulavam donos desses territórios, dessas grandes posses de terra e, para que essas pessoas pudessem morar, apenas morar, toda a produção era recolhida por esses patrões. Então, é uma necessidade de Estado mesmo em que se fez no sentido de primeiramente 
criar uma unidade de conservação; que é uma maneira de legitimar o direito de uso da terra dessa população tradicional [...]. (M. S., analista do ICMBIO, entrevista realizada em janeiro de 2016). (informação verbal).

Antes da criação da RESEX, ainda segundo o líder sindical entrevistado, as pessoas não tinham nem documento de identidade. Com a criação da RESEX, todos tiraram seus documentos; os moradores locais, segundo ele, conseguiram ter acesso às políticas públicas, passaram a não ser mais um povo esquecido, invisível (MARIN et al, 2015), além de “[...] escapar ao domínio da propriedade privada e da regulação mediada pelos mecanismos de mercado [...]" (ACSELRAD, 2014, p. 30).

Como aduz Teisserenc (2016, p. 51):

A experiência recente de criação dessas Reservas mostra, de fato, que o seu sucesso se dá, em parte, por colocar em xeque o sistema de dominação, abrindo o caminho para uma mudança significativa na estrutura de poder local e uma renovação política através da democracia, da ação participativa e de suas práticas locais.

Segundo relatos orais de moradores e líderes sindicais que lutaram para criação da RESEX, o maior receio estava relacionado à questão fundiária, uma vez que a proposta da empresa era atuar por um período de 100 anos. A partir de então, houve a articulação entre os atores sociais e o STTR de Breves. Enquanto algumas resistiram em aceitar o direito de propriedade da Ecomapuá, outras comunidades queriam discutir propostas de "desenvolvimento sustentável" que, possivelmente, segundo os "atores locais", poderiam inserir a área em uma nova dinâmica econômica.

Diante desse cenário, o que prevaleceu foi a ação contra os interesses da empresa, assim, o Sindicato dos Trabalhadores e Trabalhadoras Rurais de Breves (STTR/Breves), apoiado pela Prefeitura Municipal de Breves, Conselho Nacional das Populações Extrativistas (CNS), Empresa de Assistência Técnica e Extensão Rural do Estado do Pará (EMATER) e Colônia de Pescadores Z-62 de Breves mobilizaram-se.

No dia 25 de novembro de 2002, o STTR/Breves protocolou, junto ao IBAMA, o ofício $n^{\circ} 078$ que solicitava a vistoria técnica no local, com o objetivo de propor a criação de uma Reserva Extrativista. Conforme Magalhães (2014), Pinto (2008) e Renó, Renó e Santos (2010), este ofício contava com a assinatura do presidente do STTR/Breves e dos 395 moradores da área (na época).

Dessa maneira, os conflitos socioambientais envolvendo a criação da RESEX Mapuá, dialogando com que aduz Little (2001), possuem base material, disputas semióticas e discursivas. Ou, ainda, como afirma Acselrad (2004), os conflitos ocorrem devido 
envolverem grupos sociais com modos diferenciados de apropriação, uso e significado do território em suma, envolvem relações de disputa entre grupos ou atores sociais em torno dos "recursos naturais"/territórios.

Nesse contexto de disputas e tensões, conflitos, a RESEX Mapuá foi criada por meio do Decreto, de 20 de Maio de 2005, com uma área total de 94.463, 93 hectares (AMARAL, 2016).

\section{RESEX MAPUÁ E OS INTERESSES: uma análise crítica}

Conforme discorrido, a RESEX Mapuá foi criada a partir da mobilização política, uma "demanda da população local”, frente aos interesses da Empresa Ecomapuá Ltda ${ }^{12}$. Mas antes disso, esta empresa realizou reuniões com os moradores para tratar da proposta de transformar a área em uma Reserva de Desenvolvimento Sustentável Particular. A intenção da empresa, conforme Pinto (2008), Renó, Renó, Santos (2010), Magalhães (2014) e Amaral (2016), era de atuar na área em um sistema de concessão de uso por um período de cem anos.

Como forma de combater a proposta de territorialização ${ }^{13}$ da empresa, a mobilização política, uma "Demanda da população local" reagiu, como já expresso acima. Contudo, cabe aqui uma ponderação, entre aspas, pois, dialogando com que diz Bourdieu, há um illusio (intencionalidade/interesse); a crença nesse "jogo" de que todos estão e participam desse jogo; a construção de uma ficção, de que, coletivamente e consensualmente, são respeitadas as regras e os projetos são para o bem de todos, quando, na verdade, trata-se de uma disputa/luta de um campo (BOURDIEU, 1994, 2002a), dos "atores locais".

Portanto, a construção da RESEX Mapuá deu-se por interesses ${ }^{14}$ forjados: 1) na preservação/conservação (que compõe seus habitus); 2) de uso sustentável; 3) servindo à

\footnotetext{
12 Segundo Santos e Marin (2016, p. 266): “[...] grandes empresas madeireiras que depois de devastar o sudeste paraense migraram suas serrarias para municípios como Portel, em que empresas como a $\mathrm{ABC}$ Agropecuária e CIKEL S.A, Madeireira Lima, (no médio e alto rio Pacajá) e madeireiros (no rio Aruanã), são os agentes que criam conflitos com os quilombolas de São Sebastião de Cipoal, adentrando sobre terras tradicionalmente ocupadas para exploração intensiva da madeira e velocidade na mudança da paisagem, diferentemente do que se divulgam em planos de manejo".

$13 \mathrm{O}$ processo de territorialização é um movimento historicamente determinado pela expansão do capitalismo e seus aspectos culturais; é um dos produtos socioespaciais do movimento das contradições sociais, sob a tríade economia, política e cultura (EPC), que determina as diferentes territorialidades no tempo e no espaço, as próprias desterritorialidades e as re-territorialidades. A perda e a constituição de um novo território nasce no seio da própria territorialização e do próprio território. Contraditoriamente, a des-re-territorialização é composta por processos socioespaciais concomitantes e complementares (SAQUET, 2003).

${ }^{14}$ Interesses aqui não estão associados ao sentido maniqueísta, mas sim associado à illusio, de Bourdieu (1994), que é "um jogo que é o produto de uma relação de cumplicidade ontológica entre as estruturas mentais e as
} 
reforma agrária, assim, conciliando com a conservação e justiça social a "povos da floresta".

O primeiro interesse da "institucionalização” (criação) de RESEX é algo que já está nas suas práticas e corpos (BOURDIEU, 1985), que é a preservação/conservação, a qual, aliás, é provada pelo estudo de Alves, Silva e Castro (2014). Os autores realizaram uma análise temporal e espacial dos padrões de cobertura vegetal, por meio de imagens de sensoriamento remoto (de 1999 e 2008): "Nela observa-se que não houve modificações significativas na ocupação do solo, onde a área natural ainda se mantém bastante preservada, fato que justifica a criação da RESEX Mapuá” (ALVES, SILVA; CASTRO, 2014, p. 151).

Essa baixa perda de cobertura florestal é confirmada também no trabalho de Amaral e Freitas (2016) (Quadro 1):

Quadro 1 - Desflorestamento da RESEX Mapuá

\begin{tabular}{|l|l|l|l|l|}
\hline $\begin{array}{l}\text { Reserva } \\
\text { Extrativista }\end{array}$ & Área Total (ha) & Períodos & $\begin{array}{l}\text { Desflorestação } \\
\mathbf{( K m}^{\mathbf{2}} \mathbf{n}\end{array}$ & Percentual (\%) \\
\hline \multirow{3}{*}{ Mapuá } & \multirow{3}{*}{$93.746,34$} & $1990-1999$ & 0,1 & 0,01 \\
\cline { 3 - 5 } & & $2000-2004$ & 27,06 & 2,89 \\
\cline { 3 - 5 } & & $2005-2009$ & 0,74 & 0,08 \\
\cline { 3 - 5 } & & $2010-2014$ & 1,34 & 0,14 \\
\hline
\end{tabular}

Fonte: Elaborado por Amaral e Freitas (2016) com base no INPE/PRODES (2016).

Apesar da tendência de anseios por mudanças no uso dos recursos naturais, não somente da extração tradicional de recursos (ALVES, SILVA; CASTRO, 2014), há um fortalecimento da inserção de "práticas sustentáveis", como a criação de peixes ou outros animais silvestres, e tecnologias sociais para captação de água da chuva e banheiros; além do manejo florestal de madeira, açaí, palmito, com apoio dos técnicos do IBAMA, ICMBIO, Instituto Floresta Tropical (IFT), Empresa Brasileira de Pesquisa Agropecuária (EMBRAPA) e Memorial Chico Mendes (MCM) (AMARAL, 2016).

Outro ilussio/interesse foi servir como elemento de reforma agrária, assim como ocorreu na criação da primeira RESEX, Alto Juruá, no Acre, conciliando conservação e justiça social aos "povos da floresta" (CUNHA, 2010). Argumento esse defendido pelo então líder sindical de Breves. 
Então com a questão da RESEX foi mudando essa história. A gente começou a dizer "olha, agora vocês é que são os responsáveis por cada lote. O lote de vocês são vocês que mandam. Não tem mais que pagar porcentagem, não tem mais que receber ordem de patrão. A produção vocês vendem pra quem quiser, pra quem pagar melhor e, a partir de agora vocês são libertos, agora tem que cumprir algumas regras". E hoje, tá com 10 anos, a gente percebe uma mudança muito grande pra melhor tanto economicamente quanto ambientalmente. Melhorou muito porque ali no Mapuá era uma terra muito esquecida e aí quando cria um projeto desse de organização os governo gosta de investir (A. M., líder sindical de Breves, entrevista realizada em janeiro de 2016). (informação verbal).

Cabe enfatizar que luta por elemento de reforma agrária é uma "ação coletiva", lutas para manutenção e reorganização desse campo (BOURDIEU, 1996). Essas disputas (conflitos) seriam, em síntese, a disputa pelo controle e a apropriação dos benefícios materiais e/ou produtos simbólicos (BOURDIEU, 1989), uma luta política (BOURDIEU, 2000a; 2000b), mas conexa a um sistema de códigos, discursos e práticas (habitus) (BOURDIEU, 1986), que são as lógicas dos “atores locais".

Assim, segundo o estudo de Pádua (2006), trata-se de uma luta limitada. Isso porque as criações de RESEX possuem os seguintes objetivos: 1) não possuir nenhuma vinculação com a conservação. Dessa forma, são inadequadas como modelo de UC; 2) são criadas apenas para fins sociais e econômicos, para inclusão das comunidades residentes; 3) a criação RESEX como elemento oportunista, no qual a questão da conservação serve apenas de pretexto para a posse da terra e obtenção de benefícios políticos e econômicos (MENEZES; SIENA; RODRÍGUEZ, 2011).

A luta pela "institucionalização" (criação/construção) de Mapuá como Reserva Extrativista contribuiu para a criação de várias políticas para Reserva: PAA (Programa de Aquisição de Alimento Escolar), PNAE (Programa Nacional de Alimentação Escolar ${ }^{15}$ ), Bolsa Família, Bolsa Verde, Programa Manejo Florestal Comunitário Familiar e, ultimamente, o projeto SANEAR Amazônia ${ }^{16}$. Isso, segundo alguns relatos obtidos em campo, melhorou muito a vida da população:

Houve várias ações com a criação da Reserva. Por exemplo, a operação de tirar documentos, a grande maioria não tinham documentação. Aí tanto o governo federal quanto o municipal e o estadual também uma vez fez uma ação de tirar

\footnotetext{
15 Aquisição e produção, especialmente, de farinha de mandioca, de tapioca (Manihot esculenta), açaí (Euterpe oleracea) e de banana (Musa paradisiaca) para alimentação escolar. Produtos comprados de agricultores familiares locais.

16 Segundo Amaral (2016, p.87): “O Projeto Sanear Amazônia surge no ano de 2014 a partir do convênio do MDS (Ministério do Desenvolvimento Social e Combate à Fome) e do MCM (Memorial Chico Mendes) com participação de algumas instituições como é o caso do Centro dos Trabalhadores da Amazônia (CTA). Consiste na implantação de tecnologia social na Amazônia, como forma de melhorar a qualidade de vida dos povos que habitam a floresta (água de qualidade e saneamento básico), por meio do compartilhamento de tecnologias sociais (tecnologia de captação de água da chuva)".
} 
documento, mas o governo federal é o que mais tem investido nessa questão do documento (bolsa verde, bolsa família, seguro defeso). Até porque se não tinha documento, não tinha como acessar essas políticas. (R. B., comunidade Bom Jesus, entrevista realizada em junho de 2015) (informação verbal).

Isso tudo possibilitou identificar o papel do Estado durante o processo de “institucionalização" jurídico-burocrático, como mediador e, atualmente, financiador e facilitador de políticas construídas pela associação de moradores locais da RESEX. Possibilitou, também, na criação de parcerias com o governo federal e estadual para qualificar e capacitar os atores sociais a desenvolverem e se apropriarem de tecnologias sociais, principalmente relacionadas à área de saneamento e saúde, configurando-se uma espécie de autonomia relativa do Estado.

Cabe aqui, contudo, pontuar que a RESEX Mapuá convive com problemas de educação e saúde, principalmente a comunidade do Lago do Socó:

\begin{abstract}
Praticamente nós vive isolado aqui só com a benção de Deus. Quando nós adoece é o jeito ficar aqui parado pra ver o que acontece. Nos casos em que a gente tem condição de ir de rabeta até um posto nós vai é pro Anajás por causa de que é mais perto pra nós ir pro Anajás do que praí pro Mapuá ou pra Breves (B. S., comunidade Lago do Socó, entrevista realizada em julho de 2015). (informação verbal).

Aqui a situação estava muito complicada. Vou relatar aqui perante todos, mas é algo que é do conhecimento de todos. Dificilmente temo cloro pra tratar da água que nós consome. A secretaria de saúde não fornece esse material todo o tempo pra nós. Temos 58 família na comunidade pra distribuir esse material para tratamento da água mas passa com 3 ou até 4 meses sem distribuição. Então como nós ia tratar? Ficar dependendo o tempo todo de ir na cidade buscar isso não tem condição alguma (M.G., comunidade Bom Jesus, entrevista realizada em julho de 2015).
\end{abstract}

De acordo com dados coletados na comunidade do Lago do Socó, há apenas uma escola na área. Todos os moradores entrevistados relataram que quase não há aula e, quando há, é apenas durante quatro dias em um mês (pesquisa de campo)(Fotografias).

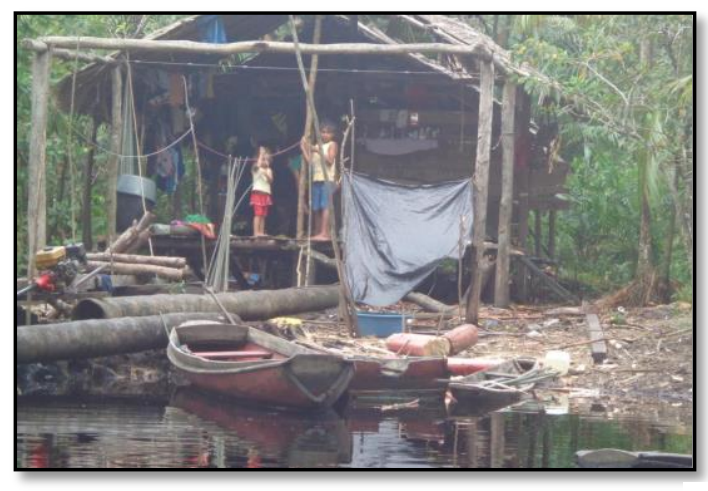

Figura 2 - Casa na comunidade Lago do Socó Foto: Vanessa Amaral (28/07/15).

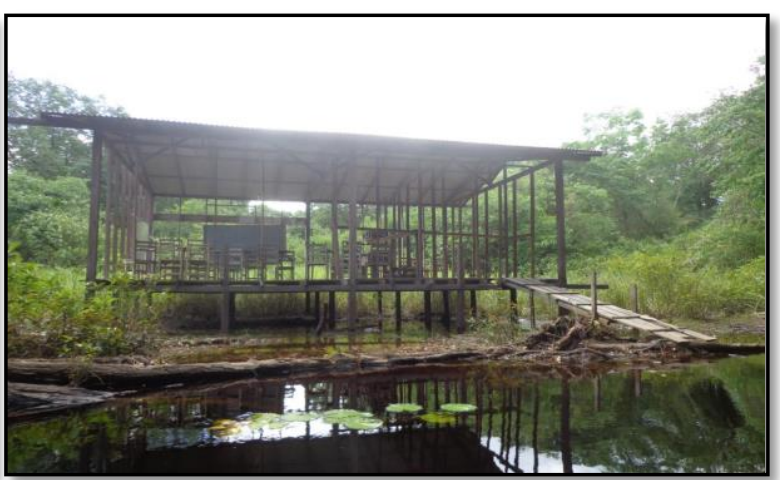

Figura 3 - fotografia da Escola na Comunidade Lago do Socó

Fonte: Vanessa Amaral (28/07/2015). 
Durante a pesquisa de campo, pode-se verificar a escola (Figura 3) “abandonada”. A última aula foi realizada no dia 17 de setembro de 2014 (data que estava escrita no quadro de aula). A fotografia foi tirada no dia 28 de julho de 2015, quase um ano depois e nada foi modificado; tudo está como foi deixado na última aula.

Isso levou à reflexão de que os sistemas democráticos não são tão democráticos (SANTOS, 2002) e que o processo de governança de recursos (processo de negociação), de áreas protegidas no Brasil (BOCKSTAEL et al., 2016), ou governança territorial (TEISSERENC, 2014) não possui "sinergia" (são harmônicas e nem vão se tornar harmônicas) entre poder público, empresas e sociedade civil, seja na criação de RESEX, seja na sua processsualidade enquanto RESEX. Em síntese, a governança de recursos configurar-se-iam a partir de um produto de uma mente sonhadora, de uma sociedade utópica (AMARAL, 2016).

\section{CONSIDERAÇÕES FINAIS}

Neste artigo, buscou-se descrever e analisar os interesses e conflitos no processo de “construção"/criação RESEX Mapuá, em 2005. Esses objetivos vão ao encontro da relevância desse estudo (justificativa), o qual visualiza os interesses que estão no jogo, as disputas, conflitos e impactos; como também dá ênfase a um estudo com foco específico, com propósito de generalizações, por meio das suas lógicas e ilussio imersos em um determinado campo (BOURDIEU, 1994).

Como pontuado no artigo, houve um crescimento substancial em termos de números e tipos de UC no Brasil, na década de 1990 (DRUMMOND; FRANCO, 2012). Hoje, o Brasil possui 325 UC (dados atualizados até maio de 2016), das quais 127 estão na região Amazônica, sendo que desse total, 45 são RESEX. O arquipélago do Marajó, no estado do Pará, possui quatro RESEX, uma delas é a RESEX Mapuá (fonte empírica de estudo nesse artigo).

A construção RESEX Mapuá, assim como outras disputas para criação de outras RESEX (TEISSERENC, 2014), é marcada não pela forest of disputes (IORIS, 2005), mas, sobretudo, por lutas para manutenção e reorganização de um campo, uma disputa pelo controle e a apropriação dos benefícios materiais e/ou produtos simbólicos, uma luta política.

A reação da população local de Mapuá (agentes desse campo) à territorialização da empresa (Ecomapuá), por meio da criação de política/projetos socioambientais conduzidos 
pela empresa, que atuaria período por 100 anos, foi, principalmente, a forte articulação entre os "atores sociais locais" e o STTR de Breves. Junto a isso, houve a necessidade de "forjar interesses"17 na construção/criação da RESEX Mapuá, dentre os quais: 1) preservação/conservação (que compõe o habitus dos “atores locais”); 2) uso sustentável; 3) servir à reforma agrária, conciliando conservação e justiça social a "povos da floresta".

O artigo aponta alguns caminhos para a compreensão de como se "construiu" uma RESEX na Amazônia (isso não quer dizer que há modelo pronto ou posto), contudo se apresenta inconclusivo-limitado, o que será possivelmente o desafio para pesquisas posteriores: identificar e comparar a criação de outras RESEX no Marajó e na Amazônia, como forma de verificar similitudes e diferenças.

A retomada dessa (objetivo, no caso) pesquisa (com criação até mesmo de uma agenda de pesquisa) seria muito importante para verificar se a criação de UC é estratégia (suficiente) mais eficaz, positivamente falando, já que, segundo o estudo de Araújo et al. (2016), em 2013, os Tribunais de Contas da União (TCU) e dos Estados (TCE) "constataram" que apenas 4\% das UC possuíam alto grau de implementação, isto é, estavam recebendo os insumos (recursos, instrumentos e infraestrutura) necessários a sua gestão. Esse estudo de Araújo et al (2016) aponta (superficialmente e sem dados empíricos) que a insuficiência de implementação as torna vulneráveis à exploração ilegal de produtos (por exemplo, madeira) e à ocupação de grileiros em milhares de hectares.

Esse artigo considera (indiretamente) que é preciso pensar e reavaliar (as reflexões de pesquisadores e do Estado), a fim de "derrubar" o assistencialismo (político e histórico), pautado em programas de transferência de renda do governo federal (Bolsa Família e Bolsa Verde), e a inúmeras proibições de uso das RESEX (MEDINA; BARBOSA, 2016). Como também é preciso a convicção de que a inserção produtiva agrícola ("salvadora") das RESEX seja o plantio de milho e soja (MEDINA; RIBEIRO; BRASIL, 2016); algo que, aliás, agricultura "sustentável” (familiar), o solo, a terra, o homem, a mulher, o Marajó e a Amazônia não desejam.

\section{REFERÊNCIAS}

ACSELRAD, H. As práticas espaciais e o campo dos conflitos ambientais. In: ACSELRAD, H. (Org.). Conflitos Ambientais no Brasil. Rio de Janeiro: Relume Dumará, 2004. p. 13-35.

\footnotetext{
17 Aqui interesses ou "forjar interesses" não é encarado de maneira maniqueísta, oportunista ou pejorativa. Configura-se em um jogo de atos/ações dos jogadores que estão imersos nas suas práticas e habitus do seu campo (de grupos), em uma disputa política, na qual é construída sua pauta política de resistência e luta.
} 
ACSELRAD, H. A crítica do "ambiente" e o ambiente da crítica. Antropolítica: Revista Contemporânea de Antropologia, v. 36, p. 27-47, 2014.

ALLEGRETTI, M. H. Política de uso dos recursos naturais renováveis: a Amazônia e o extrativismo. Revista de Administração Pública, v. 26, n. 1, p. 145-162, 1992.

ALLEGRETTTI, M. H. A construção social de políticas ambientais. Chico Mendes e o movimento dos seringueiros. 2002. 811f. Brasília. Tese (Doutorado em Desenvolvimento Sustentável) - Universidade de Brasília, Brasília, 2002.

ALLEGRETTI, M. H. A construção social de políticas ambientais. Chico Mendes e o movimento dos seringueiros. Desenvolvimento e Meio Ambiente, v. 18, p. 39-59, 2008.

ALVES, O. J. A.; SILVA, C. N.; CASTRO, C. J. N. Uso dos recursos naturais por populações tradicionais na RESEX Mapuá (Breves - Pará). Revista do Instituto Histórico e Geográfico do Pará (IHGP), n. 1, v. 01, p. 135-154, 2014.

AMARAL, V. S. Instrumentos do Estado e dos atores sociais no uso sustentável da Reserva Extrativista Mapuá - Marajó. 2016. 135f. Dissertação (Mestrado em Planejamento do Desenvolvimento) - Programa de Pós-graduação em Desenvolvimento Sustentável do Trópico Úmido, Universidade Federal do Pará, Belém, 2016.

AMARAL, V. S.; FREITAS, J. S. Estado Ineficiente Promove Reservas Extrativistas (In) sustentáveis na Amazônia. Observatorio de la Economía Latinoamericana, v. 309, p. 1 12, 2016.

ARAUJO, E.; BARRETO, P.; BAIMA, S.; GOMES, M. Quais os planos para proteger as Unidades de Conservação vulneráveis da Amazônia?. Belém: Imazon, 2016.

BACHELARD, G. A formação do espírito científico: contribuição para uma psicanálise do conhecimento. Rio de Janeiro: Contraponto, 1996.

BEZERRA, N. P.; LIMA, D. M. "Guardar é para tirar depois?”. Disputas territoriais e conceituais em uma unidade de conservação: o caso da Reserva de Desenvolvimento Sustentável Mamirauá (Amazonas - Brasil). Revista de História da UEG, v. 4, n. 2, p. 114-138, 2015.

BOCKSTAEL, E.; BAHIA, N. C. F., SEIXAS, C. S., BERKES, F. Participation in protected area management planning in coastal Brazil. Environmental Science \& Policy, v. 60 , p. $1-10,2016$.

BOURDIEU, P. Effet de champ et effet de corps. Actes de la recherche en sciences sociales, v. 59, p.73, 1985.

BOURDIEU, P. Habitus, code et codification. Actes de la recherche en sciences sociales, v. 64, p. 40-44, 1986.

BOURDIEU, P. O poder simbólico. São Paulo: Bertrand Brasil/DIFEL, 1989.

BOURDIEU, P. As razões práticas. Paris: Seuil, 1994. 
| Conflitos e interesses no processo de “construção” da RESEX Mapuá, Marajó, Pará |

| Vanessa Silva Amaral | Jondison Cardoso Rodrigues |

BOURDIEU, P. Você disse "popular"?. Revista Brasileira de Educação, n. 1, p. 16-26 1996.

BOURDIEU, P. Pascalian Meditations. California: Stanford University Press, 2000a.

BOURDIEU, P. Quelques Propos Sur Le Champ Politique. Lyon: Press University Lyon, 2000b.

BOURDIEU, P. Campo de poder, campo intelectual - itinerario de un concepto. Editorial Montressor, 2002a.

BOURDIEU, P. Condición de clase y posición de clase. Revista Colombiana de Sociologia, v. 7, n. 1, p. 119-141. 2002b.

CARDOSO, M. S. C. Pescadores da Reserva Extrativista Marinha de Soure: práticas sociais e ordenamento do território. In: MARIN, R. E. A. et al. Povos tradicionais no arquipélago do Marajó e políticas de ordenamento territorial e ambiental. Rio de Janeiro: CASA 8, 2015. p. 131-161.

CASTRO, E. M. R. "O Brasil não conhece o Brasil, o Brasil não conhece a Amazônia". Somanlu, v. 8, n. 1, p. 185-191, 2008.

CASTRO, E. M. R. Políticas de Estado e atores sociais na Amazônia contemporânea. In: BOLLE, W.; CASTRO, E.; VEJMELKA, M. (Org.). Amazônia - Região Universal e Teatro do Mundo. São Paulo: Globo, 2010. p. 105-122.

CAVALCANTI, F. C. S. A política ambiental na Amazônia: um estudo sobre as reservas extrativas. 2002. 314f. Tese (Doutorado em Ciências Econômicas) - Universidade Estadual de Campinas, Campinas. 2002.

CORNETTA, A. Direitos territoriais nas várzeas de Breves, Marajó: novos usos da floresta e distintas percepções sobre o ambiente. Novos Cadernos NAEA, v. 19, n. 2, p. 89-114, 2016.

COsTA, A. C. G.; MURATA, A. T. A problemática socioambiental nas Unidades de Conservação: conflitos e discursos pelo uso e acesso aos recursos naturais. Sustentabilidade em Debate, v. 6, n. 1, p. 86-100, 2015.

COSTA, A. P. Políticas públicas e desenvolvimento nas RESEX Verde para Sempre e Arióca Pruanã - Pará. 424f. Belém. Tese (Doutorado em Desenvolvimento Sustentável do Trópico Úmido) - Programa de Pós-Graduação em Desenvolvimento Sustentável do Trópico Úmido, Universidade Federal do Pará, Belém, 2014.

COSTA, M. M. Efetividade do plano do Marajó: uma análise do eixo infraestrutura para o desenvolvimento. 2016. 176 f. Dissertação (Mestrado em Gestão Pública) - Núcleo de Altos Estudos Amazônicos, Universidade Federal do Pará, Belém, 2016.

CUNHA, C. C. Reservas Extrativistas: institucionalização e implementação no Estado brasileiro dos anos 1990. 2010. 308 f. Tese (Doutorado em Psicossociologia de Comunidades e Ecologia Social) - Universidade Federal do Rio de Janeiro, Rio de Janeiro, 2010. 
DRUMMOND, J. A.; FRANCO, J. L. A. O mapa das UCs será o mapa da inclusão social? Natureza \& Conservação, v. 7, n. 1, p. 8-16, 2009.

DRUMMOND, J. A.; FRANCO, J. L. A An assessment of Brazilian conservation units - a second look. Novos Cadernos NAEA, v. 15, n. 1, p. 53-83, 2012.

DRUMMOND, J. A.; FRANCO, J. L. A; NINIS, A. B. Brazilian Federal Conservation Units: a historical overview of their creation and of their current status. Environment and History, v. 15, n. 4, p. 463-491, 2009.

DUMITH, R. C. Inserção das Unidades de Conservação na Legislação Ambiental Brasileira. Revista da ANPEGE, v. 9, n. 12, p. 71-87, 2013.

ECOPAMAPUÁ. A empresa. Disponível em: <http://www.ecomapua.com.br/quem a empresa.html>. Acesso em: 22 de jul. 2016.

FEARNSIDE, P. M. Conservation Policy in Brazilian Amazonia: understanding the dilemmas. World Development, v. 31, n. 5, p. 757-779, 2003.

FEARNSIDE, P. M. The evolving context of Brazils environmental policies in Amazonia. Novos Cadernos NAEA, v. 16, n. 2, p. 9-25, 2013.

FEARNSIDE, P. M. Environmental policy in Brazilian Amazonia: Lessons from recent history. Novos Cadernos NAEA, v. 19, n.1, p. 27-46, 2016.

FREITAS, J. S.; FLORENTINO, D. G.; SOUZA, J. V. F. O mito das Unidades de Conservação de Uso Sustentável da Amazônia. DELOS: Desarrollo Local Sostenible, v. 8, p. 1-22, 2015.

ICMBIO. Geoprocessamento - UC bioma resumo agosto 2016. Disponível em: <http://www.icmbio.gov.br/portal/images/stories/servicos/geoprocessamento/DCOL/ dados tabulares/UC bioma resumo agosto 2016.pdf > . Acesso em: 25 jan. 2017a.

ICMBIO. Geoprocessamento - Dados Gerais UC agosto 2016. Disponível em: <http://www.icmbio.gov.br/portal/images/stories/servicos/geoprocessamento/DCOL/ dados tabulares/DadosGerais UC agosto 2016.pdf>. Acesso em: 25 jan. 2017b.

IORIS, E. M. A forest of disputes: struggles over spaces, resources, and social identities in Amazonia. 2005. 326f. Tese (Doutorado em Philosophy) - University of Florida in Partial, Flórida, 2005.

LITTLE, P. E. Os conflitos socioambientais: um campo de estudo e de ação política. In: BURSZTYN, M. (Org.). A difícil sustentabilidade: política energética e conflitos ambientais. Rio de Janeiro: Garamond, 2001. p. 1956-2232.

LOURENÇO, R. S. S. Educação do campo e unidade de conservação de uso sustentável: um estudo a partir da Casa Familiar Rural de Reserva Extrativista Mapuá, Município de Breves, Arquipelago do Marajó, Estado do Pará. 2016. 137 f.. Dissertação (Mestrado em Gestão Pública) - Núcleo de Altos Estudos Amazônicos, Universidade Federal do Pará, Breves, 2016. 
MAGALHÃES, A. P. F. Metodologia aplicada ao turismo de base comunitária em reservas extrativistas: valoração da atividade turística - o exemplo de Mapuá, Arquipélago do Marajó, Breves/PA. 2014. 124 f. Dissertação (Mestrado em Gestão dos Recursos Naturais e Desenvolvimento Local na Amazônia) - Programa de Pós-Graduação em Gestão dos Recursos Naturais e Desenvolvimento Local na Amazônia, Universidade Federal do Pará, Belém, 2014.

MARIN, R. E. A. et al. Povos Tradicionais no Arquipélago do Marajó e Políticas de Ordenamento Territorial e Ambiental. Rio de Janeiro: Casa 8, 2015.

MARQUES, A. A. B.; SCHNEIDER, M.; PERES, C. A.. Human population and socioeconomic modulators of conservation performance in 788 Amazonian and Atlantic Forest reserves. PeerJ, v. 14, n. 14, p.1-28, 2016.

MEDINA, G.; BARBOSA, C. A questão produtiva nas Reservas Extrativistas. Novos Cadernos NAEA, v. 19, n. 2, p. 69-88, 2016.

MEDINA, G.; RIBEIRO, G.; BRASIL, E. Participação do capital brasileiro na cadeia produtiva da soja: lições para o futuro do agronegócio nacional. Revista de Economia e Agronegócio, v. 13, n. 1, p. 2-38, 2016.

MENEZES, D. S.; SIENA, O.; RODRÍGUEZ, T. D. M. Ambientalismo e concepções de RESEX, extrativismo e conhecimento no ICMBIO na Amazônia legal. REAd, v. 17, n. 2, p. 451-479, 2011.

PÁDUA, M. T. J. Instituto Chico Mendes. O ECO. 2006. Disponível em: $<\underline{\text { http://arruda.rits.org.br/oeco/servlet/newstorm.ns.presentation.NavigationServlet? }}$ publicationCode $=6 \&$ pageCode $=78 \&$ textCode $=21814 \&$ date $=$ currentDate $\&$ content $T y p e=$ html\#topo >. Acesso em: 28 jun. 2008.

PAULINO, J. S.; CUNHA, L. H. H. Unidades de Conservação: políticas ambientais e modernização institucional. Revista Cadernos de Ciências Sociais da UFRPE, v. 2, n. 5, p. 28-50, 2014.

PECCATIELlO, A. F. O. Políticas públicas ambientais no Brasil: da administração dos recursos naturais (1930) à criação do Sistema Nacional de Unidades de Conservação (2000). Desenvolvimento e Meio Ambiente, n. 24, p. 71-82, 2011.

PINTO, J. Reserva Extrativista de Mapuá: Diagnóstico Socioeconômico e Ambiental (consolidado). Breves: ICMBIO, 2008.

RENÓ, F. de A. G.; RENÓ, J. S. D.; SANTOS, M. M. D. Reserva Extrativista de Mapuá e Sustentabilidade em Breves. 55f. Monografia (Especialização em Gestão e Educação Ambiental) - Programa de Pós-Graduação em Gestão e Educação Ambiental, Universidade Salgado de Oliveira, Rio de Janeiro, 2010.

SANTOS, B. S. Reinventar a democracia. 2. ed. Lisboa: Gadis, 2002.

SANTOS, F. P. Reserva Extrativista e Reserva de Desenvolvimento Sustentável, uma pequena-grande diferença. Revista GEONORTE, v. 6, n. 25, p. 43-60, 2015. 
SANTOS JUNIOR, G. da S. Ações e políticas do Estado e da sociedade acerca da geração de renda na Reserva Extrativista Marinha de Soure, Marajó, PA. 2006. 178 f. Dissertação (Mestrado em Planejamento do Desenvolvimento) - Núcleo de Altos Estudos da Amazônia, Universidade Federal do Pará, Belém, 2006.

SANTOS, D. B.; MARIN, R. E. A. Economia madeireira no Pará: análise da regulação a partir dos autos de infração da flora. Estudos Sociedade e Agricultura (UFRRJ), v. 1, p. 263-286, 2016.

SAQUET, M. A. O território: algumas interpretações. Presidente Prudente: UNESP, 2003.

SILVA, J. B. Unidades de conservação e organizações de populações tradicionais sul-amapaenses: problemas, tendências e perspectivas. 2007. 374 f. Belém. Tese (Doutorado em Desenvolvimento Sustentável do Trópico Úmido) - Programa de PósGraduação em Desenvolvimento Sustentável do Trópico Úmido, Universidade Federal do Pará, Belém, 2007.

SILVA, J. B. et al. Sustentabilidade institucional em Reservas Extrativistas na Amazônia brasileira. Papers do NAEA, Belém, n. 316, p. 3-20, 2013.

SILVA, J. B.; SIMONIAN, L. T. L. População tradicional, reservas extrativistas e racionalidade estatal na Amazônia brasileira. Revista Desenvolvimento e Meio Ambiente (UFPR), v. 33, n. 1, p. 163-175, 2015.

SILVA, K. Conscientização, tradição e desenvolvimento: a conquista da terra, o uso dos recursos naturais e conflitos étnicos em unidades de conservação no estado do Amazonas. Revista Intratextos, v. 6, n. 1, p. 1-24, 2015.

TEISSERENC, P. A governança territorial em Reservas Extrativistas. Revista PósCiências Sociais, v. 11, n. 22, p. 19-41, 2014.

TEISSERENC, P. Poder local e condições de sua renovação na Amazônia. Novos Cadernos NAEA, v. 19, n. 1, p. 47-70, 2016.

VIÉGAS, R. N. Conflitos ambientais e lutas materiais e simbólicas. Revista Desenvolvimento e Meio Ambiente, n. 19, p. 145-157, 2009.

YIN, R. K. Estudo de caso: planejamento e métodos. Porto Alegre: Bookman, 2005. 